\title{
'IT GIVES ME MY FREEDOM: TECHNOLOGY AND RESPONDING TO BODILY LIMITATIONS IN MOTOR NEURON DISEASE
}

Amanda Pavey, Narelle Warren and Jacquelyn Allen-Collinson

People living with Motor Neuron Disease (MND) experience profound and rapidly progressing impairment. In order to maintain their physical and social functioning, people so affected employ a range of technologies and technological aids (body auxiliaries) to enhance their life and maintain wellbeing. Using a phenomenological study design, we explored the experiences of 42 men and women who had been diagnosed with MND. Although many participants initially resisted the adoption of aids (often-electronic devices that enabled continued participation in daily life) or tools (the instruments that allowed achievement of specific tasks), such technologies offered a way for people with MND to overcome, to some extent, the limitations posed by their physical degeneration. Through generating a sense of 'normality', these kinds of 'enabling' technologies promoted social engagement and the maintenance of valued relationships or activities. Technologies can provide people with MND with some positive experiences within a way of being-in-the-world that has become so difficult and challenging.

Keywords: Motor Neuron disease, body auxiliaries, enabling technologies, phenomenology, wellbeing

Running title: Enabling technologies and Motor Neuron Disease

Media teaser: In the face of rapidly progressing impairment, how do people live a life of quality? What role can technologies play in supporting people with MND to live a good life? 
AMANDA PAVEY is the Senior Regional Advisor for the Motor Neurone Disease Association of Queensland, Australia. Her research interests cohere on the embodied dimensions of chronic illness, end of life care and MND. Address correspondence to: Amanda Pavey, MND QLD, PO Box 1039, Inala East, Queensland, 4077, Australia. Email: amanda@mndaq.org.au

NARELLE WARREN is a Lecturer in Anthropology, School of Social Sciences, Monash University, Australia. She has published widely on the lived experience of chronic and neurodegenerative conditions, and is co-editor of Reframing Disability and Quality of Life: A Global Perspective (with Lenore Manderson). Address correspondence to: Narelle Warren, School of Social Sciences, Level 4, 20 Chancellor's Walk, Monash University, Victoria, 3800, Australia. Email: Narelle.Warren@monash.edu

JACQUELYN ALLEN-COLLINSON is Director of the Health Advancement Research Team (HART) and Reader in the Sociology of Sport at the University of Lincoln, UK. She has published extensively around the sociology of embodiment, particularly women's lived-body experiences, including via feminist phenomenological approaches. She is also interested in the role of identity work (from a symbolic interactionist perspective) and the embodied experience of injury and illness in sport. Address correspondence to: Jacquelyn Allen-Collinson, School of Sport and Exercise Science, University of Lincoln, Brayford Pool, Lincoln, Lincolnshire, LN6 7TS, UK. Email: jallencollinson@lincoln.ac.uk

Motor Neuron Disease (MND) is a terminal, rapidly progressing neurodegenerative disease that destroys the body's functional capabilities, including coordination, communication and respiration (Casey 2011, Eisen and Krieger 1998). Life expectancy from diagnosis is usually 
estimated at between two to five years (Holmes 2005). No definitive symptom allows for easy diagnosis, and no definitive diagnostic test is currently available (Locock, Ziebland, and Dumelow 2009). The onset of MND causes life-altering circumstances, including fundamental changes to employment, social interaction, independence and mobility (Dawson et al. 2004). Much research on MND emphasises reduced mobility and ability to communicate as the most debilitating aspects of the disease (Leigh et al. 2003, Brown and Addington Hall 2008, Hughes et al. 2005). Constantly changing symptoms impact progressively on both sufferer and caregivers, as the individual's lifestyle becomes increasingly restricted (McCabe, Roberts, and Firth 2008; Sakellariou 2015). The lived experience of MND reflects experiences of chronic illness more broadly, including generating feelings of isolation, loneliness, and being a burden to others, in addition to financial pressures, but it is a unique and particularly debilitating illness (Charmaz 1993, Jeon et al. 2009, Vassilev et al. 2010, Sakellariou 2015).

Much has been written about the challenges of living with MND (Robinson and Hunter, 1997), but with little attention given to how people obtain a sense of positivity or wellbeing despite these restrictions. Employing a phenomenological framework (Allen-Collinson and Hockey 2011, Pavey, Allen-Collinson and Pavey 2013), in this article we explore how forms of enabling technology and technological aids can enhance quality of life for people living with MND, and in doing so, highlight the tensions that sometimes emerge in living in and through a 'blended body' (Pavey 2013). We draw extensively on the idea of 'bodily auxiliaries', a concept that describes the relationship between the body and matter that is not organically attached, yet which ceases to be an external object (Merleau-Ponty 1962) and rather becomes a bodily extension. This focus on embodiment - and the social and cultural ways in which people 'live' their bodies in everyday 
life, including the practical arrangements for everyday living, which Pols (2010) terms 'knownow' - offers important insights for analysing the lived experience of those living in and through MND-affected bodies.

\section{DIFFERENT MODES OF BODILY BEING}

A healthy 'normal' body has been conceptualized as one that recedes into the background of conscious thought, and comfortably disappears (Leder 1990). This is a body that is to some extent un-mediated, hidden, and 'recessive' so that a person is not overtly aware of the bodily self as the subject of experiences (Legrand 2007). During periods of good health, the body constitutes a 'blind spot' (Crossley 2012) that is largely invisible or 'absent' (Leder 1990) to our conscious awareness. In times of illness, the body is thrust into the foreground. Leder (1990) argues that the body expresses itself in three schemes of embodiment. The recessive body refers to the hidden, inner body of internal organs and processes of which we are not usually aware, such as respiration and digestion. In contrast, the ecstatic body is defined as the 'out-standing' body that projects outward into its environment and is aware of itself via feedback mechanisms.

Prior to the onset of MND, the ecstatic body provides the main means of an individual reaching out to engage with and experience the world, including via the senses (Allen-Collinson and Pavey 2014, Legrand 2007, Leder 1990). When the body begins to 'dysfunction', the previously 'silent', recessive body, then appears to consciousness, or 'dys-appears' (Leder 1990). The $d y s$ appearing body is that which is suddenly and often forcibly brought to our conscious attention, often in experiences of pain, discomfort, illness, but also in moments of intense pleasure. It is at 
this point that the individual begins a journey towards a sense of mastery over his or her own body (Dubose 1997).

In considering the changing locus of the body in the context of a rapidly degenerating condition, we draw on Manderson's (2011) work in exploring the role of technology and technological aids in enhancing social interaction and in re-establishing, however partially, some degree of bodily control and mastery. We should emphasize that here, we focus on the more positive, 'enabling' forms of technology, although we fully acknowledge that many other technological aids that people with MND use on an everyday basis (such as breathing devices and feeding tubes, for example), are more usually experienced as highly distressing, painful and unpleasant.

Not all bodies conform to societal received notions of normality, in that bodies considered 'normal' are usually assumed to be free of illness and absent of physical impairment or disability (Manderson 2011; Warren and Manderson, 2013). Technology can provide a means of overcoming certain physical disadyantages. At the same time, technology may reduce certain social and physical barriers, for example, routine social isolation and mobility difficulties (Lupton and Seymour 2000). Williams highlights that "the reality of life for most disabled people is not the heroic overcoming of dramatic obstacles, but the daily struggle with mundane activities" (1993: 103). The use of technology can ameliorate difficulties with such daily activities. These 'body auxiliaries' (Merleau-Ponty 1962) are used by the body, but are not biologically part of the body (Salamon 2006), such as in the case of osseointegration, commonly used in orthopaedic surgery, or interocular lens, as used in cataract surgery (Manderson 2011). 
A body auxiliary thus creates possibilities by allowing an individual to exceed what might be physically possible without that object. In the context of MND, 'technology' refers to objects or machines that assist human action in some way, and enable a person to complete a given task that would not otherwise be possible (Larubia-Prado 2000). Thus, wheelchairs, modified household items, remote-controlled appliances (e.g. curtains and lights), hydraulic lifts (e.g. hoists to assist a person to get in and out of bed or bath, up and down stairs, and in and out of the home), computers, machines to aid communication, hands-free devices (e.g. phones), and voiceactivated mechanisms, are examples of technologies that can aid function and give some control to their users over their everyday life (see Sakellariou 2015). Conversely, without these devices, there may be little or no autonomy or control. Technology can also open up social space and provide enhanced physical capacity and social agency for people with significant physical impairments.

In some senses, technology offers the individual the possibility of extending the self beyond the physical limitations of the 'flesh and bone' body. The body can thus incorporate (sometimes literally) the technology or device to produce a 'blended body' (Pavey, et al. 2013). Analogous to Leder's (1990) 'absent' body, where the healthy body becomes taken-for-granted, hidden in the background, technology also becomes accepted and normalized as a means to make the body work properly once again. These 'techno-bodies' are thus considered to be "healthy, enhanced and fully functional" (Balsamo 1995: 216), perhaps in some ways bridging the gap between 'impairment' and 'normal' functioning. 


\section{THE STUDY}

To elucidate the ways in which the embodied changes of MND fundamentally affected and disrupted the everyday lives of our participants, we invited men and women aged over 18 years living in the UK or Australia who had been diagnosed with MND, to take part in the research. Participant recruitment within the UK was greatly assisted by the Dementias and Neurodegenerative Diseases Research Network (DeNDRoN), funded by the Department of Health as part of the National Institute for Health Research and the UK Clinical Research Network. The Motor Neuron Disease Association (MNDA) UK also advertised and promoted the study on its website, at Regional MND conferences, and in smaller branch meetings. Within Australia, recruitment occurred through the Motor Neuron Disease Association Australia (MNDA Australia); subsequent to permission from the executive director, the study was advertised in newsletters and on its website of the Victoria branch of the association (MNDA Victoria), as well as through local branch meetings. Via these routes, participants were invited to contact the lead author and express interest in the study. Following this, all participants were provided with an information sheet and given an opportunity to ask any questions. Written consent was sought from all participants prior to interviews being arranged. Forty-two (31 UK and 11 Australia) participants were recruited to take part in the study, including 11 female and 31 male participants, aged between 42 and 74 years. The project was granted ethical approval by the University ethics committee.

Data collection occurred in two ways. Face-to-face in-depth interviews were conducted by the first author with ten participants; these were digitally recorded and transcribed verbatim. 
Interviews occurred at a time and in a place of participants' choosing, and were structured around living with MND and the impact this had on participants' lives. An additional 32 semistructured interviews were conducted via email; this strategy allowed greater involvement from participants who might otherwise be unable to take part in the research due to the occurrence of dysarthria and dysphonia, which limited dialogue in some respects. To counter any data limitations, a greater number of participants was sought and interviewed than was initially intended in order to ensure data saturation. Data limitations were not due to participants choosing not to divulge rich information, but rather to the effect of MND on their ability to articulate verbally, particularly in a sustained way.

Data were analysed using a phenomenological thematic approach, which included the repeated close reading of transcripts, familiarizing the researchers with the data (Allen-Collinson 2011). The rich and often highly evocative narrative accounts provided vivid experiential accounts of participants' changing bodies. Salient themes and our interpretations of these were discussed with colleagues as 'critical friends' in order to challenge some of our taken-for-granted presuppositions surrounding MND (commensurate with the phenomenological approach adopted) and to aid in the formulation and clarity of shared or more idiographic themes and subthemes. Throughout the interview process, many opportunities arose for the interviewer (first author) to check with participants their understanding of the key points. She would, for example, seek participant confirmation via prompts such as: "so it sounds as if you experienced (a specific moment) in this way"(with the researcher briefly recounting an experience as had been interpreted), and "have I understood you correctly?" By repeatedly employing this practice, the interviewer was able to cross-check her initial interpretations. Furthermore, the outcomes of 
questions across participants were compared to highlight commonalities (and also divergences) of experience.

This approach to data analysis proved an effective means of identifying the many similarities of the illness experience, and therefore acted as an aid to identification of the strongest themes arising from participant accounts. Analogous to a grounded theory approach (Charmaz, 1993), we employed an iterative process during interviewing and data analysis, so that themes emergent from earlier interview transcripts could be 'fed into' subsequent interviews, thus providing an opportunity to explore the salience of any particular theme. All participants are identified here by pseudonyms.

\section{MND AND BODILY DYS-APPEARANCE}

MND fundamentally disrupted the lived bodies and everyday lives of participants. During its onset and progression, MND had a profound effect on a person's capacity to engage with the world in the taken-for-granted ways previously enjoyed. As many participants reflected, the body began to materialize as something to be reified, to be thought about (Colombetti 2011, Legrand 2007), becoming the main focus of even the most mundane of activities:

I was going downstairs, right foot first, when I fell, bumpetty bump, all the way to the bottom on my back. I thought, 'how stupid of me not to concentrate'. When it happened again a few days later, I realised I would have to hold on tight to the banister in future, and only use one hand to carry things. (Olivia) 
In highlighting the need to keep a hand free to support herself when climbing down the stairs, Olivia demonstrates the constant presence of her body. Here, in contrast to other conditions such as Multiple Sclerosis (MS) and diabetes (Koch, Kralik and Taylor 2000, Vickers 2012), the body never returns to a 'recessive' state for varying periods of time; it is generally not possible for people to view the condition as simply part of life. For those with MND, however much the person tries, the illness can never hide quietly in the background - it is always consciously experienced in everyday life:

I don't just suffer from MND and the effects of muscle wastage; I suffer from all the things connected to it. Symptoms like deep depression, severe cramp, excess saliva, poor circulation and terrible sleeping patterns are now a part of my everyday life (Brian).

Participants sought to understand and make sense of their physical deterioration in various ways. For a number of them, bodily degeneration transpired in gradual increments allowing for some plateau phases, before worsening again. Other participants, however, reported the deterioration as constant: "Deterioration is very slow but relentless. This makes it very wearing in the long term on carers, who inevitably are some family members as well as outsiders" (James).

The trajectory of MND differs vastly from one person to another, and the participants involved in this study illustrated this in describing their own lived experiences. The uncertainty related to this variability emerged saliently, and participants coped with this by taking each day as it came: "Every day is a new challenge because the disease is on-going, getting worse, so what you could do yesterday, you might not be able to do tomorrow" (Ellie). 
For many, each day became a time of 'testing' what could, and what could not be achieved. The impact of this on individuals, and the realization of a (sometimes daily) reduction in the body's abilities evoked sentiments of anger, regret, disappointment and worry. This was often tinged with sadness, despair and hopelessness "The big problem with all this is that there is no cure for MND, so whatever comfort the hospital staff give me, there is a downward spiral and no one (at the moment) can save me" (Bob). Against the unpredictability of MND progression, technology offered participants a way of minimizing these disruptions, and supported them to live the best life they could achieve.

\section{EMBRACING TECHNOLOGY}

Our participants adopted and utilized all kinds of 'tools' and 'aids' to continue and enhance forms of their bodily engagement with the world. Here the body is offered an opportunity, afforded by technology, to extend outwards again, in a somewhat blended and hybrid fashion, to re-join and experience the world in a different but appreciated way. This may constitute some reestablishment of a secondary relationship with the ecstatic bodily self (Leder 1990, Woodgate 2001).Central to the inclusion of technology in a participant's life was the feeling of freedom it could engender, leading to changes in attitude to visiting new places when assistive aids were introduced. In many cases, participants reported visiting only 'tried and tested' venues, for fear of meeting an unmanageable obstacle somewhere new. After original reluctance and even resistance to embracing various aids, many participants reported that their attitudes towards such assistive devices had fundamentally altered, and the aids were subsequently cited as invaluable means of regaining a degree of independence: 
Over the years, my attitude has changed considerably. Originally, I resisted the need to use a wheelchair and stuck (stubbornly) to using a stick. This was stupid; I would fall a lot and had to park very close to where I was going. I needed to find a route where I would have a wall or fence on my left which I would use to lean on (with walking stick in right hand) (Andrew).

After a chance 'trial' period in a wheelchair, Andrew realised that rather than the wheelchair making him impaired, it was actually his own self-confessed stubbornness that was keeping him impaired. Embracing 'wheels' bought independence and 'enablement' back into his life:

Using a lift was a long process, as unless I was right beside the lift door I could never make it in time. I would guess which one would come first and then wait at that lift until eventually that one arrived. Looking back, using a walking stick [rather than a wheelchair] was a ludicrous situation but had anyone talked to me about it, I would have ignored them, or worse still, told them to mind their own business. Common sense did not prevail until I was coming back from holiday, at the airport I was in a wheelchair to be pushed around but I found I could move around on my own with it (Andrew).

After accepting the help afforded by assistive aids, many acknowledged that they would never 'get over' (Briscoe and Woodgate 2010) their illness, as might have been possible with another illness. The use of body auxiliaries made it, at least on some level, possible to 'get through' (Briscoe and Woodgate 2010) certain barriers generated by the illness, to adapt and move beyond the confines of the MND body: "I trialled several models [of rollator, a wheeled walkingframe] and decided to purchase one with a seat. This meant that I was still able to get around 
without the risk of falling and when the pain in my legs became too bad I could sit down" (Olivia).

By viewing technology as an extension of themselves, as a body auxiliary, participants were unwilling to accept that their body was a less mobile body: they therefore saw the adoption of technological advances as offering possibilities to enhance the physical self or delay the impact of progressive impairment. Ellie, for example, spoke about the freedom her electric wheelchair afforded which contrasted ironically with the sedentary nature of being in the wheelchair: "I stay in my wheelchair most of the day because it gives me my freedom to move around."

Over a period of time, participants began to acknowledge, recognise and embrace a relationship with the variety of adaptive aids that enabled them to maintain some parts of their previous, more 'able' life. Certain technologies seemed to promote a sense of standing still, like a plateau, within the illness pathway, arresting feelings of relentless decline. Further, 'tools' - objects which facilitated the completion of tasks related to daily living, such as a bed tray or shower seat provided a means of successfully and effectively negotiating a sense of bodily normality. For example, although Ellie still required the help of her husband or a carer to do certain tasks that required movement to and from the chair, she felt grateful that at least she was able to move, or 'walk' as she described it, with people from one room to the next using her electric wheelchair, when she wanted. 


\section{Hybridization: reluctance and realization}

Participants commonly spoke of the advantages that emerged from their adoption of adaptive aids, without which they could not subsequently imagine their life. Despite their expressions of positivity over this, no participant reported experiencing a straight forward, linear leap from living an 'able' to this new 'hybrid' body, as evidenced by the period of initial struggle described by Andrew (above). Many described a moment of realization that, no matter what actions they took to prevent it, physical deterioration would occur regardless, as Fay described:

There's a Tesco (supermarket) about a mile... just over a mile and a half down the road. Well I thought the more I walk, the more I'll be able to walk ok on the levels, and now I know I must have looked like a drunken old bag walking down the road. But to me, you know, I thought the more I did the stronger I would become, but it wasn't to be...

For a woman who was once a very keen hiker, not even being able to walk 'on the levels' down to the local shop was a particularly low point. Other participants spoke about 'learning the hard way' about their new capabilities. In Jacob's case, despite knowing deep down what he could and could not do, it was not until he fell that he realised and then accepted how life had irrevocably changed for him. Summarizing bluntly, he noted the options available to him, unless he chose to embrace technology: "[Without a wheelchair] I've got three choices now; sit down, lie down or fall down" (Jacob). 


\section{Information Communication Technology (ICT)}

Empowerment via technology presented in many forms. The use of 'virtualizing' technology, a highly utilized form of technological hybridity in contemporary British society, emerged within this study, particularly in the form of on-line technology and communication. Such technology opened avenues for participants, providing them with opportunities to discover fresh modes of embodiment - potentially changing the nature of their embodiment itself - and generating new ways of engaging with the world. Several participants spoke with great enthusiasm about the opportunities the internet afforded them, which occurred in a variety of ways: "My laptop is very important to me and brings the outside world in. It is my preferred method of communication as I find talking on the telephone challenging for me and the listener. I use e-mail, Yahoo messenger, and Skype and regularly stay in contact with friends and family" (Judith).

With reliance on such technologies by participants, the boundaries between 'self' and 'other' were dissolving, with the interfaces between humans as biological organisms and machines becoming cloudy and blurred. Vicky, for example, was keen to advocate the use of email, which she felt permitted her to present herself in a more socially normative way: "I can do my photos, my research, planning my trips, dealing with the company in Cape Town, emailing travel agents.... I sound more normal on e-mail" (Vicky).

The value of certain types of technology to those with communication difficulties emerged strongly during interviews, and participants also spoke of the merits of internet use for communication: 
I had the good fortune to become ill after the invention of the laptop, which means that I am able to access unlimited information from my settee, and contact friends throughout the world. (Olivia)

The internet makes a huge difference; you can do almost anything online. (Judith)

Similarly, Vicky used text messaging with great frequency throughout her day. A key advantage for her was that her phone was easily portable, and could be slipped into a pocket when she needed both hands to use her rollator to move around the house: "Oh yeah, texting! It's my lifeline! I'm text incontinent!" (Vicky)

In face-to-face communication with the 'public', participants reported the problematic nature of others' perceptions of the MND sufferer as intellectually impaired: "The main problem I have is the general public perception of 'someone who is a little slow', both in speech and movement, therefore I must also have some sort of intellect problem and [they] treat me as such" (Tanya). In contrast, participants felt they had more control of their presentation of self in the virtual world, including their email communications: "I come across as 'me' in email" (Vicky). The use of speech aids was also highlighted. While Andrew, for example, had accepted the fact that he was going to lose his voice, he intended to do all he could to 'retain' as much of his voice as possible. For him, this meant resisting becoming entirely reliant on augmentative aids:

I have a Palmtop (a portable lightwriter) which I use to help my speech. It is a great boost to my confidence that with it, I can always get the message across - some would say that I should use it more but I want to retain my voice (poor as it is) for as long as possible (Andrew). 
In these ways, technology provided a means of re-establishing or recreating a favoured selfidentity, via email or other forms of online communication. It created the opportunity for control over the presentation of a very different self, which contrasted to their lack of control over the physical self on many dimensions. The meanings ascribed to these assistive aids by some participants were that they had simply become part of them, incorporated, so that such aids were a component of the 'extended self' (Allen Collinson 2009) where body and aid/technology were lived as an integrated whole.

\section{THE FUTILITY OF TECHNOLOGY}

The positive aspects of such embracing of technology should not be over-stated, particularly given the decline of the physical body. Despite methods of enhancing individual independence through technology, for some participants, MND had already begun to incapacitate them to an all-encompassing extent. At this juncture, their physical capabilities declined to such a point that little wilful movement was possible, and total dependence upon others was necessary. At this point, participants moved to a sense of resignation: regardless of technology, and the past positive interactions with it, no amount of body-technology hybridity was going to halt corporeal decline: "I am trapped in my body. My care has now become 24 hour high need care. I am not able to do anything for myself. I am still able to think. I no longer leave the house" (Chris).

To maintain connection with the 'outside world', participants also noted the importance of suitable public amenities. Ellie, for example, observed that, despite having someone to help her and having the necessary adaptive aids to get to the bathroom, she was considerably hindered by 
the lack of appropriately designed public facilities: "When we want to go away, we are limited to places that can cope with my disabilities. It's the same with days out, which we love, there's always the worry of the disabled loos not being good enough, so I have to wear incontinence pads in case. Now I know why babies cry so much!” (Ellie). As this became a more frequent occurrence and suitable venues became harder to locate, outings reportedly dwindled as tasks became further hindered by the continuous physical decline. At this juncture, the individual often appeared to arrive at the realization that they were to become largely housebound.

\section{DISCUSSION}

Participants found the bodily disruptions engendered by MND difficult to relegate to a background presence; their narratives were characterized by vivid descriptions of never being able to forget the body. Similar to Sartre's (1966) discussions of the way pain experiences change the mind-body-world relationship, MND caused disruptions to the previous taken-forgranted being-in-the-world. The accounts related here, we argue, support the notion that MND fundamentally and irreversibly disrupts and forever changes the lived experience of the world (Colombetti 2011; Sakelleriou 2015), affecting the way reality is experienced, prompting the 'unfamiliar' to emerge (Oyebode 2009). At this juncture, the recessive nature of the body becomes irrevocably lost for most; instead the body pushes forward, often vividly, into the foreground of the individual's consciousness, becoming the focus of intentionality.

At times, participants described their bodies in relation to what was, and what was no longer possible. The 'dys-appearing' body (Leder 1990) brings itself to the forefront of consciousness, 
presenting itself as disruptive and threatening. This seems to suggest that the onset of impairment strips individuals of the opportunity to continue enjoying the 'seductively predictable flow' (Hockenberry 1995) of their previously enjoyed life. Our data suggest that a new chapter of 'perception and action' (Zeiler 2010) begins with the onset of decline, where MND necessitates the need for the reorganization and re-evaluation of the persons' mind-body-world relation. Such occurrences engendered 'spatio-temporal constriction' (Leder 1990): as the person's attention becomes drawn away from wider worldly matters and external social engagement, it becomes more focused on the bodily here and now. Moreover, our findings suggest, this is accompanied by experiences of a profound loss of freedom, spontaneity, identity, sense of self, and feelings of alienation and loneliness. It is thus evident that this changes the perception of self, and also the perceived perceptions of others, leading to a profound sense of social displacement (Manderson 2011).

Taken together, our research findings highlight the ways in which people with MND embraced, often following initial reluctance, the use of technological aids - which they generally considered as forms of bodily auxiliaries - in order to counteract in some ways the increasing impairment and decline of their physical bodies, at least to a certain point. There is great potential for the impaired self when combined or blended with technology. In this, there presents an opportunity for a person to undergo a learning process, or adopt 'a playing self' (Melucci 1996), which makes it possible to renegotiate the boundaries presented by the impaired, restricted body. Here, people with MND draw on their 'know-now' (Pols, 2010), their applied expertise of using technologies to produce desired outcomes or achieve specific goals in which functional limitations can be mitigated. In doing so, a multiplicity of a 'reassembled' and 'reconstructed' 
self (Haraway 1990) is created, and the normative, socially taken-for-granted body is challenged. Such combinations or 'composites' of bodies and technology is commensurate with MerleauPonty's (1962) notion of mind-body-world interconnectedness, which problematizes neat distinctions between the internal and the external world, for the body 'extends' toward an object and beyond its own boundaries. This, we argue, constitutes a secondary ecstatic body. For example, the use of an electric wheelchair or rollator becomes an integrated part of the body, a tactile and transformative element, a 'limb' so integral to daily life and function that the individual may wish never to be separate from it. Although not entirely unconsciously, such aids become part of their body, with individuals seeing a given aid as giving them back some 'freedom' and 'independence'. In this way, these aids essentially differ from the tools (e.g. catheters, feeding tubes, etc) which facilitate the achievement of daily activities.

Advanced industrialized nations are currently at the forefront of technological advancements in terms of mobility apparatus, and these extensions of the body have opened up opportunities for people with many different types of impairment (Howe 2011). Goodley and Runswick-Cole (2011) postulate that the true potential of the cyborg body lies in its uncertainty and multiplicity. Translating this to those with MND, such technology changes the certainty of incremental physical decline, and disability commensurate with MND, into the uncertainty of various possibilities to reinvent and maintain some semblance of the self, to reshape and reconstruct identity. 'Body' technology has the potential to empower individuals with complex physical needs (Howe 2011). 
In this study, at least, embracing technology appears to have an overwhelmingly positive affect. Where there are no answers in terms of cure, and few options for symptom management, individuals seemingly turn to technology to seek ways of combating the rapid and uncontrollable advancement of their impaired world. Here, there emerges an opening toward optimism, excitement, new horizons - and this was evident when it came to 'tools' involving the internet. For people with disabilities more widely, inclusion of ICT in day to day lives has been shown to be closely linked to issues of independence, quality of life, and empowerment (Schoech, Cavalier, and Hoover 1993, Vicente and Lopez 2010). For participants, the internet was described as an essential coping strategy, providing them with a method of taking some control over their illness and independence. More broadly, ICT has the possibility to reduce certain disabling barriers that impair and prevent participation in many activities (Ritchie and Blanck 2003). In these ways, technology can help generate some degree of optimism as the individual becomes influenced and awakened to its possibilities. This is especially salient given the constructions of future life with MND which characterize the somewhat limited duration left as seemingly hopeless, and reduced in opportunity and spontaneity. Such a view coheres with studies of disability more generally, where individuals living with impairment have been found to indicate the use of ICT as a method of enhancing their decision making capacity through being able to access information (Waldron, Lavitt, and Kelley 2000).

A cautionary note on the positive possibilities of technologically-assisted embodiment is also necessary, for whilst it was apparent that technology could 'enable' in many ways, there was a point at which it was no longer able to overcome or compensate for the extensive decline of the physical self. Thus there appears to be two main points of displacement between the body and 
the 'hybrid' or 'blended' body. On the one hand, at the onset of symptoms there is a psychologically-inclined barrier toward accepting a union between self, body and technology. Here, identity, the loss and relinquishment of a 'normal' way of functioning, and the concern of being seen by others using and adopting adaptive aids appears to be a key factor in not embracing a hybrid, technologically facilitated body; this was further forestalled by earlier, negative experiences of MND-related technologies, such as feeding tubes. At the other end of the illness cycle, as death draws nearer, the body itself rejects, prevents and resists such blending. The physical decline incapacitates the ability of the person to interact with objects and tools that exist around her or him, thus this lack of ability ultimately prohibits any desired engagement.

However keenly individuals advocated the positive aspects of technology, at no point did any participant appear to display total integration or 'corporeal absorption' of the aids or tools they utilized. Rather, they appeared to be comfortable (at least to some extent) with them, utilizing them as a means to keep going out and doing what they wanted to do, to enjoy life as far as they could, where they could, and continue some semblance of a 'normal' life as far as possible. Practitioners have an essential role in supporting individuals autonomously to negotiate the possibilities offered by technology in managing the inevitable physical declines of MND.

\section{ACKNOWLEDGMENTS}

We thank the Motor Neuron Disease Associations of the UK and Australia for their cooperation and help throughout the research process. Ethical approval was obtained from the appropriate University of Exeter (UK) Ethics Committee. 


\section{STATEMENT ON FUNDING}

Narelle Warren was supported by a National Health and Medical Research Council (NHMRC) Australian Research Training Fellowship (GNT0606785, 2010-2014).

\section{DECLARATION OF CONFLICTING INTERESTS}

The author(s) declared no conflicts of interest with respect to the authorship and/or publication of this article.

\section{REFERENCES}

Allen-Collinson, J.

2011 Intention and epochē in tension: Autophenomenology, bracketing and a novel approach to researching sporting embodiment. Qualitative Health Research in Sport, Exercise and Health 3(1):48-62.

Allen-Collinson, J. and J.Hockey

2011 Feeling the way: Notes toward a haptic phenomenology of distance running and scuba diving. International Review for the Sociology of Sport 46(3):330-345.

Allen-Collinson, J. and A. Pavey

2014 Touching moments: Phenomenological sociology and the haptic dimension in the lived experience of Motor Neurone Disease. Sociology of Health \& Illness 36(6):793-806. 
Allen Collinson, J.

2009 Intimate intrusions revisited: A case of intimate partner abuse and violations of the territories of the self. Qualitative Sociology Review 5(1):50-69.

Balsamo, A.

1995 Forms 01 Technological Embodiment; Reading the Body in Contemporary Culture.

Cyberspace/cyberbodies/cyberpunk: Cultures of technological embodiment 43:215-237.

Briscoe, W. P. and R. L. Woodgate

2010 Sustaining self: The lived experience of transition to long-term ventilation. Qualitative Health Research 20(1):57-67.

Brown, J. and J. Addington Hall

2008 How people with motor neuron disease talk about living with their illness: A narrative study. Journal of Advanced Nursing 62(2):200-208.

Casey, K. S.

2011 Creating an assistive technology clinic: The experience of the Johns Hopkins AT Clinic for patients with ALS. NeuroRehabilitation 28(3):281-293.

Charmaz, $\mathrm{K}$.

1993 Good Days, Bad Days: The Self in Chronic Illness and Time. New Brunswick, NJ: Rutgers University Press.

Colombetti, G. 
2011 Varieties of pre-reflective self-awareness: Foreground and background bodily feelings in emotion experience. Inquiry 54(3):293-313.

Crossley, N.

2012 Merleau-Ponty, medicine and the body. In Contemporary Theorists for Medical Sociology. G. Scrambler, ed. Pp. 87-103. Abingdon, Oxen: Routledge.

Dawson, S., L. J. Kristjanson, C. M. Toye and P. Flett

2004 Living with Huntington's Disease: Need for supportive care. Nursing and Health Sciences 6(2):123-130.

Dubose, J. T.

1997 The phenomenology of bereavement, grief, and mourning. Journal of Religion and Health 36(4):367-374.

Eisen, A. and C. Krieger

1998 Amyotrophic Lateral Sclerosis: A Synthesis of Research and Clinical Practice. New York:

Cambridge University Press.

Glaser, B. G. and A. L. Strauss

2005 [1965]. Awareness of Dying. New Brunswick, NJ: AldineTransaction.

Goodley, D. and K. Runswick-Cole

2011 Celebrating cyborgs: Photovoice and disabled children. Paper presented at the ESRC

Seminar Series: Researching the Lives of Disabled Children and Young People, with a Focus on 
Their Perspectives. Seminar. January 21. In the Norah Fry Research Unit, Bristol University, Bristol, UK.

Haraway, D.

1990 A manifesto for cyborgs: Science, technology, and socialist feminism in the 1980s.

Socialist Review 80(15):65-107.

Hockenberry, J.

1995 Moving Violations: War Zones, Wheelchairs, and Declarations of Independence. New York: Hyperion.

Holmes, T.

2005 Motor neuron disease and the NSF for long-term neurological conditions. Primary Health Care 15(9):27-31.

Howe, P. D.

2011 Cyborg and supercrip: The paralympics technology and the (dis)empowerment of disabled athletes. Sociology 45(5):868-882.

Hughes, R. A., A. Sinha, I. Higginson, K. Down, and P. N. Leigh.

2005 Living with motor neuron disease: lives, experiences of services and suggestions for change. Health and Social Care in the Community 13(1):64-74.

Jeon, Y. H., B. Essue, S. Jan, R. Wells and J. A. Whitworth

2009 Economic hardship associated with managing chronic illness: a qualitative inquiry. BMC Health Services Research 9(1):182-193. 
Koch, T., D. Kralik and J. Taylor

2000 Men living with diabetes: Minimizing the intrusiveness of the disease. Journal of Clinical Nursing 9(2):247-254.

Larubia-Prado, F.

2000 Franco as cyborg: 'The body re-formed by politics: Part flesh, part machine'. Journal of Spanish Cultural Studies 1(2):135-152.

Leder, D.

1990 The Absent Body. Chicago: University of Chicago Press.

Legrand, D. P. M.

2007 Pre-reflective self-consciousness: On being bodily in the world. Janus Head 9 (2):493-519.

Leigh, P. N., S. Abrahams, A. Al-Chalabi, M. A. Ampong, L. H. Goldstein, J. Johnson, R. Lyall, J. Moxham, N. Mustfa, and A. Rio

2003 The management of motor neuron disease. British Medical Journal 74 (Suppl 4):32-47.

Locock, L., S. Ziebland, and C. Dumelow

2009 Biographical disruption, abruption and repair in the context of motor neuron disease.

Sociology of Health and Illness 31(7):1043-1058.

Lupton, D. and W. Seymour

2000 Technology, selfhood and physical disability. Social Science and Medicine 50(12):18511862. 
Manderson, L.

2011 Surface Tensions: Surgery, Bodily Boundaries, and the Social Self. Walnut Creek, CA: Left Coast Press.

McCabe, M. P., C. Roberts and L. Firth

2008 Work and recreational changes among people with neurological illness and their caregivers. Disability and Rehabilitation 30(8):600-610.

Melucci, A.

1996 The Playing Self: Person and Meaning in the Planetary Society. Cambridge: Cambridge University Press.

Merleau-Ponty, M.

1962 [1945] Phenomenology of Perception. London: Routledge.

Oyebode, F.

2009 Feelings of being: Phenomenology, psychiatry and the sense of reality. British Journal of Psychology 195:464-465.

Pavey, A. C.

2013 A Phenomenologically Inspired Journey into the Lived Experience of Motor Neuron

Disease. PhD dissertation, Department of Sport and Social Sciences, University of Bath.

Pavey, A., J. Allen-Collinson, and T. Pavey 
2013 The lived experience of diagnosis delivery in motor neuron disease: A sociologicalphenomenological study. Sociological Research Online 18(2):11-18.

Pols, A. J.

2010 Bringing bodies - and health care - back in. Exploring practical knowledge for living with chronic disease. Medische Antropologie 22(2):413-427.

Ritchie, H. and P. Blanck

2003 The promise of the Internet for disability: a study of on-line services and web site accessibility at Centers for Independent Living. Behavioral Sciences and the Law 21(1):5-26.

Salamon, G.

2006 "The place where life hides away": Merleau-Ponty, Fanon, and the location of bodily being. differences 17(2):96-112.

Sakellariou, D.

2015 Home modifications and ways of living well. Medical Anthropology, 34(3): pages

Sartre, J. P.

1966 [1943]. Being and Nothingness. New York: Washington Square.

Schoech, D., A. R. Cavalier and B. Hoover

1993 Using technology to change the human services delivery system. Administration in Social Work 17(2):31-52. 
Vassilev, I., A. Rogers, C. Sanders, A. Kennedy, C. Blickem, J. Protheroe, P. Bower, S. Kirk, C. Chew-Graham and R. Morris

2010 Social networks, social capital and chronic illness self-management: A realist review. Chronic Illness 7(1):60-86.

Vicente, M. R. and A. J. Lopez

2010 A multidimensional analysis of the disability digital divide: Some evidence for Internet use. The Information Society 26(1):48-64.

Vickers, M. H.

2012 Financial turning points and transactions for people with multiple sclerosis: Towards sustainable employment outcomes. Journal of Management and Organisation 13(3):346-362.

Waldron, V. R., M. Lavitt and D. Kelley

2000 The nature and prevention of harm in technology-mediated self-help settings: Three exemplars. Journal of Technology in Human Services 17(2-3):267-293.

Warren, N. and L. Manderson

2013 Reframing disability and quality of life: contextual nuances. In Reframing disability and quality of life: A global perspective. Warren, N. and L. Manderson, eds. Pp. 1-16. Dordrecht, NL: Springer.

Williams, G.

1993 Chronic illness and the pursuit of virtue in everyday life. In Worlds of Illness: Biographical and Cultural Perspectives on Health and Disease. A. Radley, ed. Pp. 92-108. London: Routledge. 
Woodgate, R.

2001 Symptom Experiences in the Illness Trajectory of Children with Cancer and Their Families. PhD dissertation, Faculty of Nursing, University of Manitoba.

Zeiler, K.

2010 A phenomenological analysis of bodily self-awareness in the experience of pain and pleasure: on dys-appearance and eu-appearance. Medicine, Health Care and Philosophy, 13(4):333-342. 